\title{
PHOSPHATING OF STEEL IN LOW-TEMPERATURE SOLUTION
}

\author{
${ }^{1}$ Grigory STUDENEKIN, ${ }^{1}$ Diana MAZUROVA, ${ }^{1}$ Aleksey ABRASHOV, ${ }^{1}$ Nelya GRIGORYAN, \\ ${ }^{1}$ Tigran VAGRAMYAN
}

${ }^{1}$ MUCTR - D. Mendeleev University of Chemical Technology of Russia, Moscow, Russia, mazurova@muctr.ru

https://doi.org/10.37904/metal.2021.4177

\begin{abstract}
At present, the research in the field of energy and resource-saving phosphating technologies is being continued, including the processes of applying adhesive and anticorrosive phosphate layers. The phosphating used in the industry is energy-intensive due to the high operating temperatures of the processes, which is necessary to obtain high-quality coatings in a technologically acceptable time. In addition, traditional zinc phosphate solution phosphating processes operating at moderate to low operating temperatures typically use sodium nitrite salts as an accelerating agent. In the course of the studies, we have found that the introduction of an ecologically safe nitrogen-containing accelerator into the phosphating electrolyte makes it possible to reduce the temperature of the phosphating process down to room temperature and to abandon toxic nitrate and nitrite compounds.
\end{abstract}

We have carried out studies of the low-temperature sedimentation process of crystalline phosphate coatings, which allows to obtain phosphate layers with an increased protective ability (PA). We have developed lowtemperature phosphating solutions, operating at a temperature of $20-27{ }^{\circ} \mathrm{C}$, allowing to obtain adhesive phosphate coatings with a specific weight of $3.0 \mathrm{~g} / \mathrm{m}^{2}$, suitable as an underlayer for paint and varnish coatings, and anticorrosive coatings with a specific weight of $7.5 \mathrm{~g} / \mathrm{m}^{2}$. It was revealed that phosphate layers of various thicknesses are formed from the same solution at different temperatures. They can be used to form anticorrosive layers for oiling with a specific gravity of up to $8.0 \mathrm{~g} / \mathrm{m}^{2}$ and adhesion layers for coloring with a specific gravity of up to $5.0 \mathrm{~g} / \mathrm{m}^{2}$.

Keywords: Low-temperature phosphating, corrosion protection, conversion coatings, surface treatment.

\section{INTRODUCTION}

Crystalline phosphate coatings are often used as an adhesive underlayer under paint and varnish coatings, including the processes of cataphoretic dyeing [1-3]. Strong adhesion to the surface of the product, the roughness and porosity of such layers cause good adhesion of the organic coating to the surface of the product. It is believed that the contribution of the phosphate coating to improving the adhesion of the paintwork is due to an increase in the true surface of the painted product, which leads to an increase in the amount of chemical bonds formed between the base and the paintwork. The absorption of the paint by micropores of the phosphate layer and chemical reactions between unsaturated resins of the paintwork material and phosphates included in composition of the phosphate coating also play important role in the improvement of the adhesion. Finally, due to low electrical conductivity, phosphate films protect the metal well from the underfilm corrosion the spread of corrosion spots that occur under the paintwork layer, for example, when it is mechanically damaged. Phosphating is a rather energy-consuming process, since the operating temperatures of phosphating solutions traditionally used in industry reach $55-90^{\circ} \mathrm{C}$. The use of such temperatures leads to increased energy consumption and sludge formation, also a need to change and clean the heating elements [4]. There are scientific publications in which the possibility of carrying out the process at low temperatures is 
investigated [5-14]. However, phosphating compositions contain derivatives of nitric or nitrous acids, which complicate cleaning of the wastewater. Such improvements as reduction of the toxicity of solutions and improving the quality of the resulting coatings are required.

\section{EXPERIMENTAL MATERIALS}

For the preparation of phosphating solutions, reagents of "pure", "chemically pure" qualifications and distilled water were used. The acidity of the solutions was controlled by the addition of a $\mathrm{NaOH}$ solution. As samples for the deposition of phosphate coatings, plates of cold-rolled low-carbon steel 08 were used.

The samples were degreased and activated before coating. Surface morphology was studied using a LEXTOSL 4100 Olympus confocal microscope.

The main characteristics of the phosphate coatings are the specific gravity of the phosphate layer, the mass of the base metal etched off in the process, and the protective ability, assessed by the accelerated method using Akimov's reagent. Anti-corrosive phosphate coatings with a mass of at least $5.0 \mathrm{~g} / \mathrm{m}^{2}$ are treated with oils, while coatings with a mass of not more than $5.0 \mathrm{~g} / \mathrm{m} 2$ are allowed for coloring (for electrophoretic painting less than $3.5 \mathrm{~g} / \mathrm{m}^{2}$ ).

The protective ability (PA) of phosphate coatings was determined by the drop method using a solution of the composition CuSO4 $5 \mathrm{H} 2 \mathrm{O} 82 \mathrm{~g} / \mathrm{l} ; \mathrm{NaCl} 33 \mathrm{~g} / \mathrm{l} ; 0.1 \mathrm{~N} \mathrm{HCl} 13 \mathrm{ml} / \mathrm{I}$ (Akimov's reagent). The method is an applying of a drop to the surface of the phosphate coating, the reagent reacts with iron in the pores of the phosphate film, changing the color of the drop. Thus, it is possible to estimate the protective ability of coatings in seconds [15].

The corrosion resistance of the surface of phosphated and painted with polyester powder paint Ecocolor PE RAL 9016 / P steel after treatment in the Ascott S450iP salt spray chamber was evaluated in accordance with [16] and the international standard ASTM B117 (SCAB test). The width of propagation of underfilm corrosion from the notch $\mathrm{h}(\mathrm{mm})$ was measured.

The adhesion of polyester powder paint Ecocolor PE RAL 9016 / P was determined in accordance with the international standard ASTM D 3359 and with a help of an Elcometer 107 adhesion tester using the lattice notch method.

\section{EXPERIMENTAL}

In order to develop a process for low-temperature phosphating of steel, it was decided to study the solution, depositing the coating at temperatures relatively low for existing technologies $-20-30^{\circ} \mathrm{C}$.

Preliminary experiments have shown the possibility of forming phosphate coatings in a low-temperature solution with a minimum amount of components - salt-forming zinc ions and phosphoric acid anions when using hydroxylamine as an accelerator introduced into the solution instead of the well-known accelerators of nitrite and sodium nitrate. It was found that the optimal concentration of the accelerator required for the formation of the highest quality phosphate coatings in the temperature range from 20 to $30^{\circ} \mathrm{C}$ is in the range from 2.0 to $3.5 \mathrm{~g} / \mathrm{l}$ for each phosphating composition. At a lower concentration, coatings with a lower protective ability are formed, often discontinuous, and an increase in concentration does not lead to a significant change in the properties of the phosphate layers. Therefore, the optimal concentration of hydroxylamine is taken as $2.5 \mathrm{~g} / \mathrm{l}$.

It was found that at room temperature, continuous phosphate coatings are deposited in certain ranges of concentrations of layer-forming components, highlighted in gray in (Figure1). 
It was found that coatings with high protective characteristics are deposited from the compositions in which the molar ratio of zinc ions to phosphoric acid anions is 1: 4. An increase in the concentration of phosphoric acid in solutions above certain values leads to a decrease in the protective characteristics of the coatings.

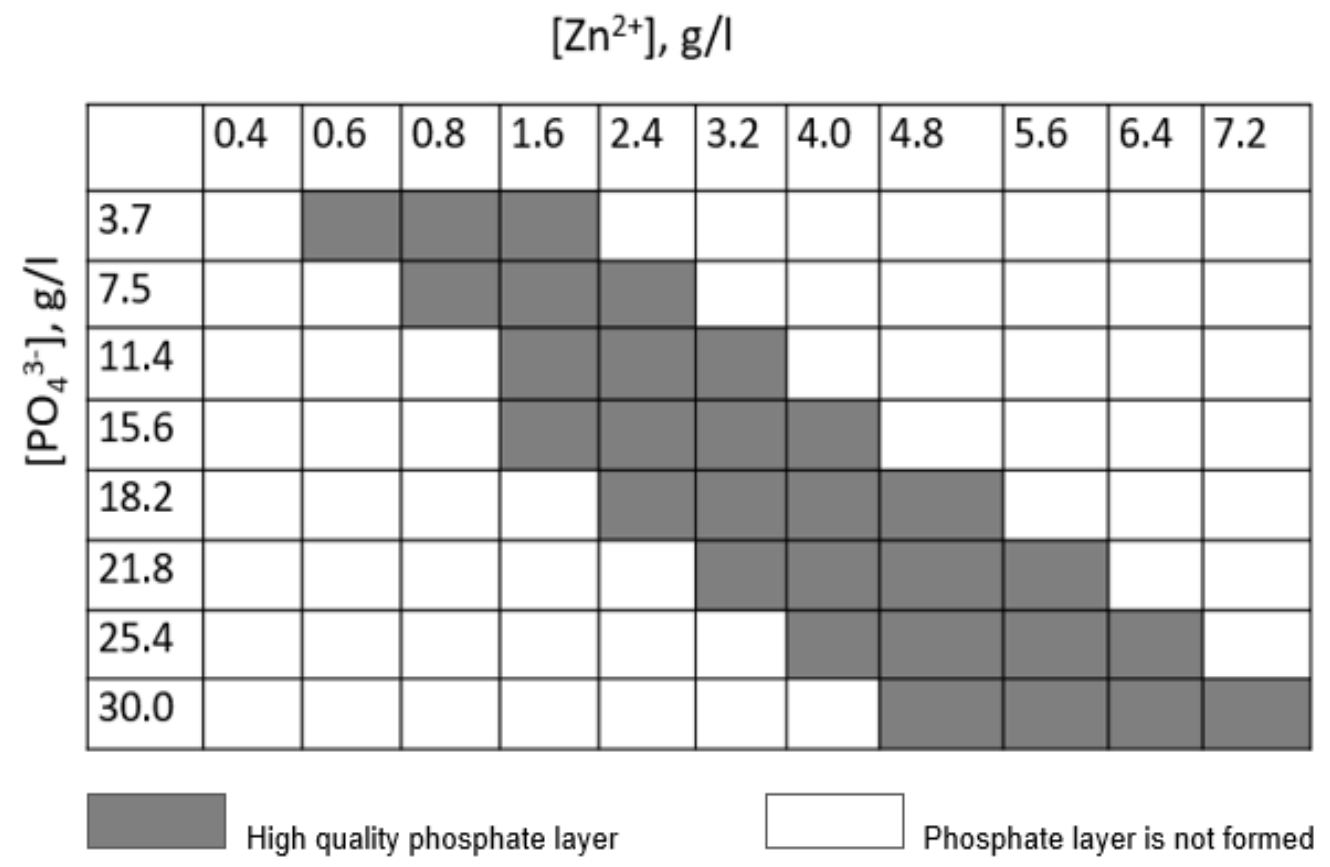

Figure 1 Appearance of the phosphate coatings depending on the concentration of the layer-forming components in the solution

Thus, a number of compositions from the previously considered concentration range were determined, with the optimal ratio of layer-forming ions (Table 1).

Table 1 Compositions of the phosphating solutions

\begin{tabular}{|c|c|c|c|c|c|c|c|c|}
\hline \multirow{2}{*}{$\begin{array}{c}\text { Component, } \\
(\mathbf{g} / \mathbf{l})\end{array}$} & \multicolumn{9}{|c|}{ Phosphating solution } \\
\cline { 2 - 11 } & $\mathbf{1}$ & $\mathbf{2}$ & $\mathbf{3}$ & $\mathbf{4}$ & $\mathbf{5}$ & $\mathbf{6}$ & $\mathbf{7}$ & $\mathbf{8}$ \\
\hline $\mathrm{Zn}^{2+}$ & 0.8 & 1.6 & 2.4 & 3.2 & 4.0 & 4.8 & 5.6 & 6.4 \\
\hline $\mathrm{PO}_{4}{ }^{3-}$ & 3.7 & 7.5 & 11.4 & 15.6 & 18.2 & 21.8 & 25.4 & 30.0 \\
\hline
\end{tabular}

Figure 2 shows the main characteristics of the phosphate coatings formed in these solutions in 15 minutes of the process. It was found that an increase in the concentration of layer-forming ions leads to a gradual increase in the specific gravity of the coatings, however, a significant increase in the protective ability is observed only up to a certain concentration, an increase above does not give noticeable advantages in protective characteristics.

The Figure 2 shows that solutions with a zinc concentration of less than $2 \mathrm{~g} / \mathrm{l}$ form layers with a low mass. As a solution that forms an adhesive phosphate coating, it is advisable to use 3-5 solutions, in which layers weighing up to $4.5 \mathrm{~g} / \mathrm{m}^{2}$ with a good protective ability are formed (70 seconds). Solutions with a concentration of more than $5 \mathrm{~g} / \mathrm{l}$ of zinc ions are suitable as independent anticorrosive layers for oiling. Anti-corrosive phosphate coatings with a mass of at least $5.0 \mathrm{~g} / \mathrm{m}^{2}$ are treated with oils, while coatings with a mass of not more than $5.0 \mathrm{~g} / \mathrm{m}^{2}$ are allowed for coloring (for electrophoretic painting less than $3.5 \mathrm{~g} / \mathrm{m}^{2}$ ). Such masses comply with the recommendations for phosphating, including ensuring good physical and mechanical properties and increasing the corrosion resistance of paint and varnish coatings. The maximum specific gravity 
of the phosphate film is formed in 15 minutes and is about $7.5 \mathrm{~g} / \mathrm{m}^{2}$. The maximum value of the protective ability, measured by the drop method using Akimov's reagent (PA), is 160 seconds with a process duration of 25 minutes. A further increase in the duration of the process leads to a slight decrease in the thickness of the phosphate layer, but at the same time, apparently, the pores of the coating are filled with precipitated phosphates, which is the optimal phosphating time at a given temperature.

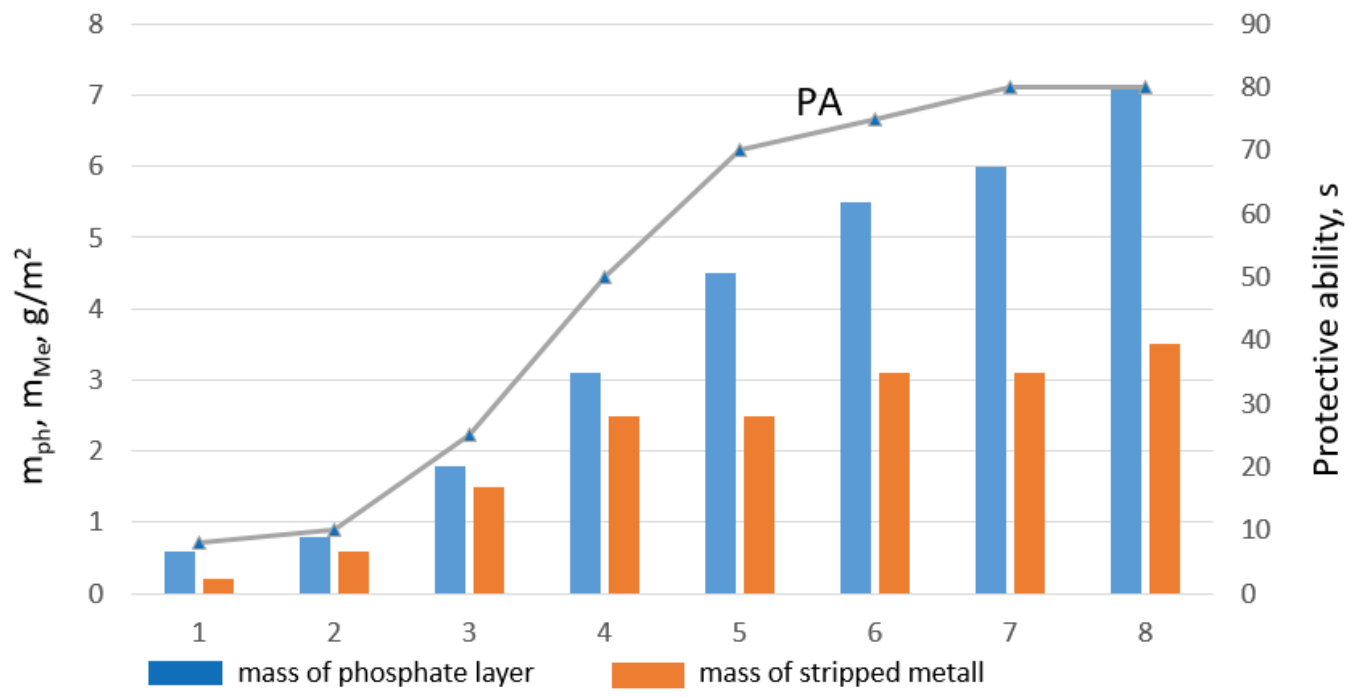

Figure 2 Dependence of the mass of the phosphate layer mph, the mass of the etched metal mMe, and the protective ability of PA on the composition of the phosphating solutions

It was found that at different temperatures phosphate films of various thicknesses are formed from the same solution, at a phosphating solution temperature of $50^{\circ} \mathrm{C}$, phosphate layers are formed in a shorter time. In this solution, a layer with a specific gravity of $5 \mathrm{~g} / \mathrm{m}^{2}$ with the highest protective ability of 180 seconds is formed in 5 minutes.

A decrease in the concentration of zinc ions in solution makes it possible to obtain adhesive phosphate coatings with a lower specific gravity of $3.0 \mathrm{~g} / \mathrm{m}^{2}$, suitable as an underlayer for paint coatings applied by cataphoresis and anaphoresis painting. It was determined that at a temperature of $20-22^{\circ} \mathrm{C}$, coatings with a protective capacity of 20 seconds are formed in 10 minutes of the process. It was found that painted phosphate coatings have exceptionally good adhesion (according to ASTM D3359) - class 0 , which have not deteriorated even after corrosion tests.

It has been established that it is possible to use an aqueous dispersion of diamond nanoparticles with a concentration of $0.1 \mathrm{~g} / \mathrm{l}$ as an activator for phosphating to increase the protective characteristics of the phosphate coating. It is shown that the use of this activator leads to an increase in the protective ability of the coatings from 20 to 35 seconds with a slight increase in the specific mass of the phosphate layer to $3.2 \mathrm{~g} / \mathrm{m}^{2}$ with a preliminary exposure of 30 seconds in this aqueous dispersion. Thus, this activation composition can be used as a replacement for traditional industrial activators of the phosphating process.

Examination of the surface of the samples using a microscope have revealed an obvious difference between the coatings formed in solutions of different operating temperatures. The operating temperature of the phosphating solution has a significant effect on the roughness of the forming phosphate layers. As it can be seen from (Figure 3), at room temperature the film is coarser and rougher (roughness value $R z=5.854 \mu \mathrm{m}$; $\mathrm{Ra}=0.866 \mu \mathrm{m}$ ), at a temperature of $50^{\circ} \mathrm{C}$, a film with small "crosslinked" crystals and lower roughness is formed (roughness value $R z=3.309 \mu \mathrm{m} ; R a=0.563 \mu \mathrm{m}$ ). 


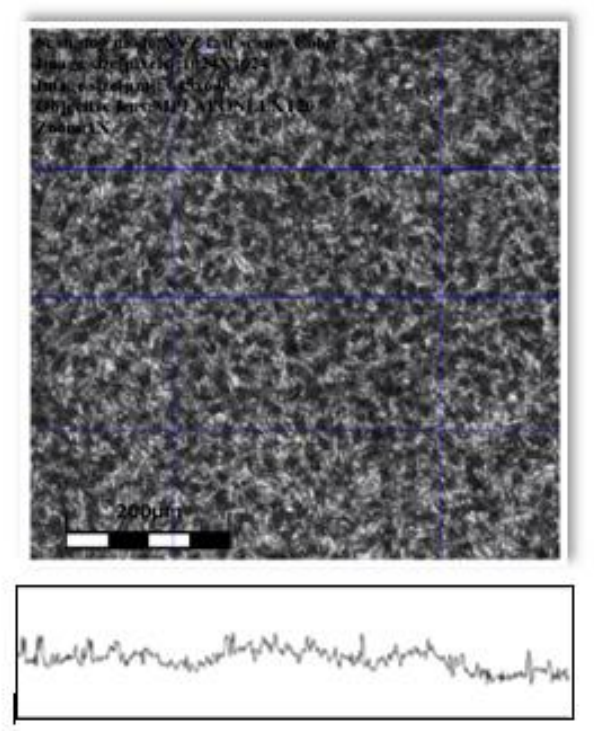

a

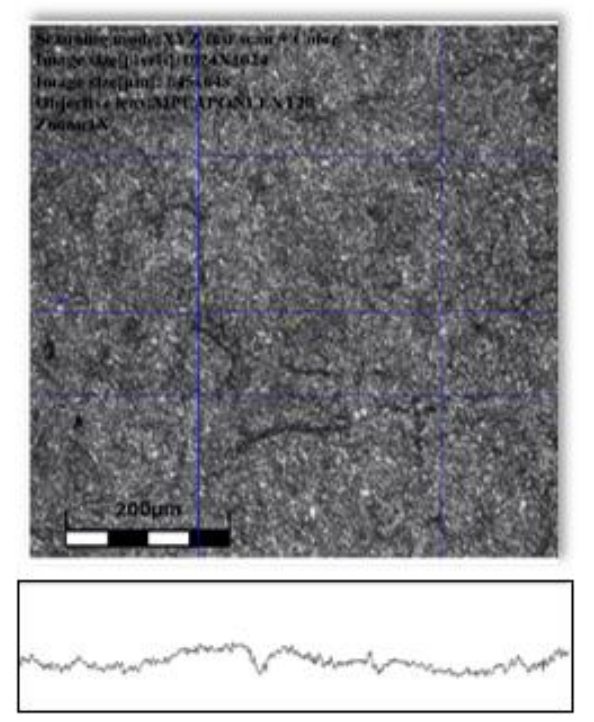

b

Figure 1 Photos and surface roughness of phosphate coatings, formed at $22^{\circ} \mathrm{C}(\mathrm{a})$ and $50{ }^{\circ} \mathrm{C}$ (b)

Corrosion tests carried out according to [16] showed that the investigated phosphate coatings do not corrode for 15 minutes in a sodium chloride solution, and oiled phosphate coatings formed in a low-temperature solution do not corrode for 2 hours. Thus, the layers formed in the test solution at room temperature can be used as independent anticorrosive coatings. Corrosion tests of painted adhesive phosphate coated steel samples in a salt spray chamber for 240 hours showed that the phosphate layers deposited at $50{ }^{\circ} \mathrm{C}$ met the requirements of ASTM B117.

\section{CONCLUSION}

It is shown that the use of an aqueous dispersion of diamond nanoparticles with a concentration of $0.1 \mathrm{~g} / \mathrm{las}$ an activator leads to an increase in the protective ability of coatings with a slight increase in the specific mass of the phosphate layer

Solutions of low-temperature phosphating have been developed, allowing to obtain phosphate coatings with a specific gravity of $3.0 \mathrm{~g} / \mathrm{m}^{2}$ with satisfactory protective properties to protect steel against corrosion in combination with paint-and-lacquer coating applied by the method of anaphoresis or cataphoresis painting and phosphate layers weighing $5.0-7.5 \mathrm{~g} / \mathrm{m}^{2}$ with an increased protective ability. The optimal conditions for the process of obtaining crystalline coatings for subsequent oiling and coloring have been determined.

A significant reduction in energy consumption is achieved by reducing the operating temperature of the phosphating solution to $20-30^{\circ} \mathrm{C}$.

Carrying out the process at lower temperatures will reduce the energy costs of production and increase the competitiveness of the developed process in comparison with the existing steel phosphating technologies.

\section{ACKNOWLEDGEMENTS}

The work was supported by the Mendeleev University of Chemical Technology of Russia. Project Number X-2020-028

\section{REFERENCES}

[1] OGLE, K., BUCHHEIT, R. G. Conversion Coatings, Corrosion Protection. Encyclopedia of electrochemistry. Wiley-VCHVerlag, 2007. 
[2] SANKARA NARAYANAN, T.S.N.. Surface pretreatment by phosphate conversion coatings - areview. Reviews on Advanced Materials Science. 2005, vol. 9, pp. 134-152.

[3] DONOFRIO, J. Zinc phosphating. Metal finishing. 2010, vol. 108, no. 11-12, pp. 40-56.

[4] ABRASHOV, A.A., GRIGORYAN, N.S., VAGRAMYAN, T.A., AKIMOVA, E.F. Improvement of Solutions for Crystalline Phosphating. Electroplating \& Surface treatment. 2010, vol. 18, no 3, pp. 48-52.

[5] PENG-TAO. Establishment of Environmentally Acceptable Room-Temperature Phosphating Process and Evaluation of Corrosion Resistance of Phosphating Coating. Reviews on Advanced Materials Science. 2005 , no. 9, pp. 134-137.

[6] ELSHAMI, A. A., BONNET, S., KHELID, J.A., SAIL, L. Novel anticorrosive zinc phosphate coating for corrosion prevention of reinforced concrete. European Journal of Environmental and Civil Engineering. 2017, vol. 21, no. 5, p. 572.

[7] THOMAS, R., UMAPATHY, M.J. Environment Friendly Nano Silicon Dioxide Accelerated Zinc Phosphate Coating on Mild Steel Using a Series of Surfactants as Additives. Silicon. 2017, vol. 9, pp. 675-688.

[8] MAZUROVA, D.V., GRIGORYAN, N.S., KAPUSTIN, Y.I., VAGRAMYAN, T.A. Optimization of low-temperature crystalline phosphatization of steel surfaces. CIS Iron and Steel Review. 2019, vol. 17, pp. 43-46.

[9] ZE-MIN CHEN, PIN LU, YAN JIA. A new low-temperature Zinc-based phosphating technology. Materials Protection. 2010, vol. 43, pp. 63-72.

[10] XIAN-JU XIAO, XUE-HONG TANG. Development of Zinc series phosphating solution at room temperature. China Resources Comprehensive Utilization. 2007, vol. 25, pp. 8-9.

[11] FANG, F., JIANG, J.H., TAN, S.Y., MA, A.B., JIANG, J.Q. Characteristics of a fast low-temperature zinc phosphating coating accelerated by an ECO-friendly hydroxylamine sulfate. Surface and Coatings Technology. 2010, vol. 15, no. 204, pp. 2381-2385.

[12] ABRASHOV, A.A., CHAMASHKINA, N.N., JURJEVA, G.A., GRIGORJAN, N.S., VAGRAMJAN, T.A. Improvement in the phosphating process. Electroplating \& Surface treatment. 2012, vol. 19, no. 4, pp. 41-46.

[13] KHALID ABDALLA, HUSSAIN ZUHAILAWATI. Activation of zinc phosphate coating by silver nitrate pretreatment. Surface engineering. 2017, vol. 33, no. 7, pp. 492-498.

[14] SONG, Y.K., MANSFELD, F. Development of a Molybdate-Phosphate-Silane- Silicate (MPSS) coating process for electrogalvanized steel. Corrosion Science. 2006, no. 48, pp. 154-164.

[15] GOST 9.401-91. Unified system of corrosion and ageing protection. Paint coatings. General requirements and methods of accelerated tests on resistance to the action of climatic factors. RU: Standardinform, 2007.

[16] GOST 9.302 - 88. Unified system of corrosion and ageing protection. Metal and non-metal inorganic coatings. Control methods. RU: Standardinform, 1990. 